\title{
Implementasi Sistem Pendukung Keputusan Penerima BSPS Desa Ciawang Menggunakan Metode SMART
}

\author{
Ois Raisa ${ }^{1}$, Herlan Sutisna ${ }^{2}$, Tuti Alawiyah ${ }^{3}$, Mumun Surahman ${ }^{4}$ \\ 1,2,3,4 Universitas Bina Sarana Informatika \\ 1ois.rsh@bsi.ac.id, ${ }^{2}$ herlan.her@bsi.ac.id, ${ }^{3}$ tuti.tah@bsi.ac.id, ${ }^{4}$ mumun.msr @bsi.ac.id
}

\begin{abstract}
Swadya Housing Stimulant Assistance is houses built on community initiatives and efforts, either individually or in groups, which include repairs or construction of new homes and the environment. In the process of selecting Swadya Housing Stimulant Assistance, village officials still experience difficulties, such as in determining which population should be prioritized to get Swadya Housing Stimulant Assistance, and there is not yet a good assessment standard to assess prospective applicants who will be submitted or prioritized. The purpose of this study is to make a Decision Support System to choose which poor people should be prioritized to get BSPS assistance, by using the SMART (Simple Multi-Attribute Rating Technique) method as a reference in making decisions on determining BSPS recipients with criteria determined by the village. The results of this study create a decision support system for the acceptance of BSPS in Ciawang Village, the process of determining the recipient of assistance can facilitate the village in producing a more effective decision in getting recipients who deserve BSPS assistance.
\end{abstract}

Keywords: Implementation of Decision Support Systems, BSPS Recipients, Smart Methods

\begin{abstract}
Abstrak: Bantuan Stimulan Perumahan Swadya merupakan rumah-rumah yang dibangun atas prakarsa dan upaya masyarakat, baik secara sendiri atau berkelompok, yang meliputi perbaikan, atau pembangunan rumah baru beserta lingkungan. Dalam proses penyeleksian Bantuan Stimulan Perumahan Swadya petugas desa masih mengalami kesulitan, seperti dalam penentuan penduduk mana yang harus di prioritaskan mendapat Bantuan Stimulan Perumahan Swadya, dan belum adanya standar penilaian yang baik untuk menilai calon pemohon yang akan di ajukan atau di prioritaskan terlebih dahulu. Tujuan dari penelitian ini adalah membuat Sistem Pendukung Keputusan untuk memilih masyakat miskin mana yang harus diutamakan mendapat bantuan BSPS, Dengan menggunakan metode SMART (Simple Multi Attribute Rating Technique) sebagai acuan dalam mengambil keputusan penentuan penerima BSPS dengan kriteria yang sudah ditentukan oleh pihak desa. Hasil dari penelitian ini membuat sistem pendukung keputusan penerimaan BSPS pada Desa Ciawang maka proses penentuan penerima bantuan dapat memudahkan pihak desa dalam menghasilkan keputusan yang lebih efektif dalam mendapatkan penerima yang layak mendapat bantuan BSPS.
\end{abstract}

Kata kunci: Sistem Pendukung Keputusan, Penerima BSPS, Metode Smart

\section{A. PENDAHULUAN}

Menurut UU No 11 Tahun 2009 pasal 1 dan 2 tentang Kesejahteraan Sosial. Pasal (1) Kesejahteraan Sosial adalah kondisi terpenuhinya kebutuhan material, spiritual, dan sosial warga negara agar dapat hidup layak dan mampu mengembangkan diri, sehingga dapat melaksanakan fungsi sosialnya. (2) Penyelenggaraan Kesejahteraan Sosial adalah upaya yang terarah, terpadu, dan berkelanjutan yang dilakukan Pemerintah, pemerintah daerah, dan masyarakat dalam bentuk pelayanan sosial guna memenuhi kebutuhan dasar setiap warga negara, yang meliputi rehabilitasi sosial, jaminan sosial, pemberdayaan sosial, dan perlindungan sosial. 
Program BSPS ini adalah untuk mendorong masyarakat berpenghasilan rendah membangun sendiri rumah yang layak huni, sehat dan aman. Tujuannya ialah terbangunnya rumah yang layak huni, sehat dan aman. Dana untuk program ini berasal dari APBN. (Qomaria, 2015)

Masyarakat miskin di Desa Ciawang membangun rumah jauh dari kriteria layak huni, kondisi rumah bisa dilihat dari atap rumah yang berlubang dan bocor, jendela rumahnya tidak mempunyai pencahayaan dan ventilasi, dinding rumah yang keropos atau terbuat dari bambu dan bata, lantai rumah yang beralaskan tanah dan berlubang, serta tidak memiliki kamar mandi.

Dalam proses penyeleksian Bantuan Stimulan Perumahan Swadya petugas desa masih mengalami kesulitan, seperti dalam penentuan penduduk mana yang harus di prioritaskan mendapat Bantuan Stimulan Perumahan Swadya, sedangkan calon pemohon lebih banyak dari pada kuota yang disediakan, sehingga belum adanya standar penilaian yang baik untuk menilai calon pemohon yang akan di ajukan atau di prioritaskan terlebih dahulu. Saat ini proses penilaian di Desa Ciawang hanya sebatas perkiraan saja tanpa adanya penilaian yang sesuai dengan kondisi pemohon yang sebenarnya, sehingga pada saat calon pemohon yang nantinya diajukan oleh desa memang layak untuk menerima Bantuan Stimulan Perumahan Swadya. Diperlukan Sistem Pendukung Keputusan menggunakan metode smart untuk memilih masyakat miskin mana yang harus diutamakan untuk penerima Bantuan Stimulan Perumahan Swadya.

\section{B. TINJAUAN PUSTAKA}

1. Sistem Pendukung Keputusan

DSS lebih ditujukan untuk mendukung manajemen dalam melakukan pekerjaan yang bersifat analitis dalam situasi yang kurang terstruktur dan dengan kriteria yang kurang jelas. DSS tidak dimaksudkan untuk mengotomatisasikan keputusan, tetapi memberikan perangkat interaktif yang memungkinkan pengambilan keputusan untuk melakukan berbagai analisa untuk melakukan analisa menggunakan model-model yang tersedia. (Syahputra, Syahrizal, Nasution, \& Purba, 2019)

\section{Bantuan Stimulan Perumahan Perumahan Swadya}

Menurut (Qomaria, 2015) menyatakan bahwa "Bantuan Stimulan Perumahan Swadya merupakan rumah-rumah yang dibangun atas prakarsa dan upaya masyarakat, baik secara sendiri atau berkelompok, yang meliputi perbaikan, pembugaran/ perluasan atau pembangunan rumah baru beserta lingkungan.

\section{Kemiskinan}

Menurut (Informatika \& Terapan, 2015) " Kemiskinan adalah keadaan dimana terjadi ketidakmampuan untuk memenuhi kebutuhan dasar seperti makanan, pakaian, tempat berlindung, pendidikan, dan kesehatan

\section{Rumah tidak Layak Huni}

Menurut (Khouf, Informatika, Komunikasi, Informatika, \& Surakarta, 2017) mengatakan bahwa "Perbaikan RTLH (Rumah Tidak Layak Huni) atau bedah rumah merupakan salah satu cara pemerintah untuk memberikan kesejahteraan bagi warga miskin.

\section{METODE PENELITIAN}

Metode SMART (Simple Multi Attribut Rating Technique), Menurut (Sanjaya, Khairina, \& Maharani, 2015) Metode SMART merupakan suatu teknik pembuatan keputusan yang menggunakan banyak kriteria (Multi Attribute). Dalam SMART pemberian nilai bobot dari tiap alternative terhadap attribute yang ada dilakukan secara langsung dengan menggunakan skala 1-100. Proses pembobotan dan penilaian pada metode ini diberikan oleh perusahaan atau seorang yang berhak mengambil keputusan atas objek yang diteliti.

Proses Pemodelan Metode SMART

Urutan dalam penggunaan metode SMART sebagai berikut :

1. Menentukan banyaknya kriteria digunakan.

2. Menentukan bobot kriteria pada masing-masing kriteria dengan menggunakan interval 1100 untuk masing-masing kriteria dengan prioritas terpenting.

3. Hitung normalisasi dari setiap kriteria dengan membandingkan nilai bobot kriteria dengan jumlah bobot kriteria. Menggunakan rumus : 
Normalisasi $=$

$$
\frac{w_{j}}{\sum w_{j}}
$$

$W_{j}$ adalah merupakan nilai bobot dari suatu kriteria. Sedangkan

$\sum W_{j}$

adalah merupakan total jumlah bobot dari semua kriteria

4. Memberikan nilai parameter kriteria pada setiap kriteria untuk setiap alternatif.

5. Menentukan nilai utiliti dengan mengonversikan nilai kriteria pada masing-masing kriteria menjadi nilai kriteria data baku. Nilai utiliti diperoleh dengan menggunakan persamaan : $u_{i}\left(a_{i}\right)=\frac{\left(C_{\text {out }}-C_{\min }\right)}{\left(\mathrm{C}_{\max }-\mathrm{C}_{\min }\right)}$

6. Menentukan nilai akhir dari masing-masing kriteria dengan mengalikan nilai yang didapat dari normalisasi nilai kriteria data baku dengan nilai normalisasi bobot kriteria. Kemudian jumlahkan nilai dari perkalian tersebut.

$$
u\left(a_{i}\right)=\sum_{J=i}^{m} w_{j} u_{i}\left(a_{i}\right)
$$

Pada persamaan 3, $u\left(a_{i}\right)$ adalah merupakan nilai total alternatif, $w_{j}$ adalah merupakan hasil dari normalisasi bobot kriteria dan $u_{i}\left(a_{i}\right)$ adalah merupakan hasil penentuan nilai utiliti.

\section{HASIL DAN PEMBAHASAN}

\section{Analisis Kebutuhan}

Dalam sistem usulan berbasis website ini terdapat dua pengguna yang dapat saling berinteraksi yaitu: Pemohon dan Admin.

\section{A. Kebutuhan Pengguna}

a. Skenario Kebutuhan Bagian Pemohon BSPS

$>$ Melakukan pendaftaran

$>$ Melakukan pengajuan proposal BSPS

$>$ Melihat hasil Penilaian

b. Skenario Kebutuhan Admin

$>$ Melihat data pengajuan

$>$ Memvalidasi kelengkapan persyaratan

$>$ Mengelola menu kriteria

$>$ Mengelola menu subkriteria

$>$ Melakukan penilaian

$>$ Mengakses nilai akhir

$>$ Mencetak hasil

\section{B. Kebutuhan Sistem}

> Pemohon harus melakukan pendaftaran terlebih dahulu agar mendapatkan username dan password.

> Pemohon harus melakukan login terlebih dahulu untuk dapat mengakses aplikasi ini dengan memasukkan username dan password agar privasi masing-masing pengguna tetap terjaga keamanannya.

> Sistem berisi menu pendaftaran, menu proposal, menu persyaratan, menu data pemohon, menu kriteria, menu subkriteria, dan menu penilaian .

> Sistem melakukan perhitungan dari data yang telah di input, hasil skor dari penilaian akan dianalisa menggunakan metode Smart untuk mendapatkan nilai tertinggi penerima BSPS.

> Admin dapat melihat data pengajuan Bantuan Stimulan Perumahan Swadaya.

$>$ Admin dapat memvalidasi kelengkapan persyaratan, apabila persyaratan lengkap pengajuan diterima.

> Admin dapat mengelola menu kriteria dan subkriteria dimana di dalamnya dapat menambahkan, mengubah dan menghapus. 
IJSE - Indonesian Journal on Software Engineering, Vol.5, No. 2, Desember 2019, $42-50$ pISSN: 2461-0690 I eISSN: 2714-9935

Admin dapat melakukan penilaian dimana didalamnya dapat menambahkan, mengubah, dan menghapus.

Pemohon dapat melihat hasil seleksi.

\section{Desain Database}

a. Rancangan Diagram Use case

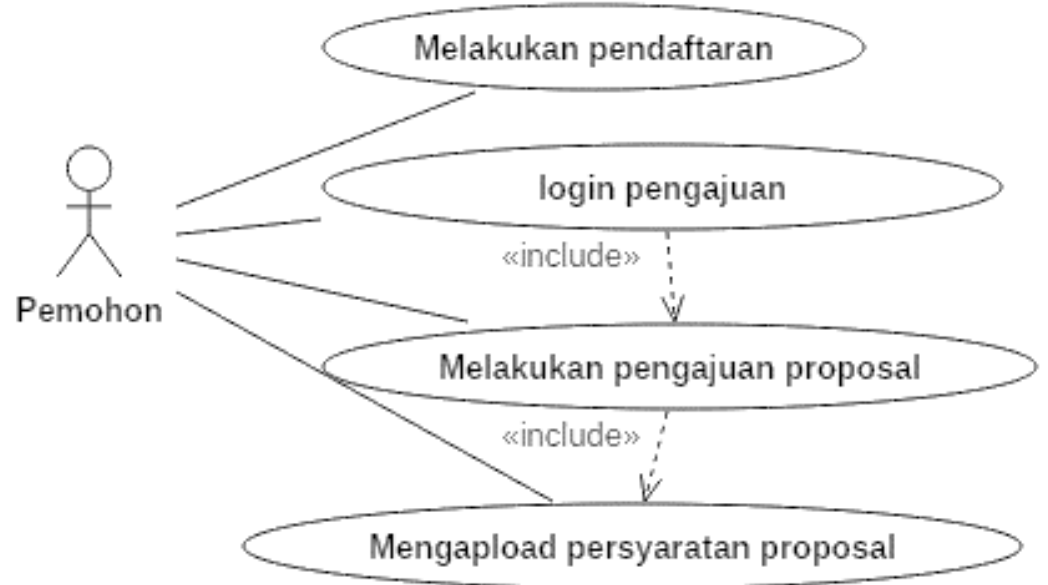

Sumber: (Penelitian, 2019)

Gambar 1. Class Usecase diagram

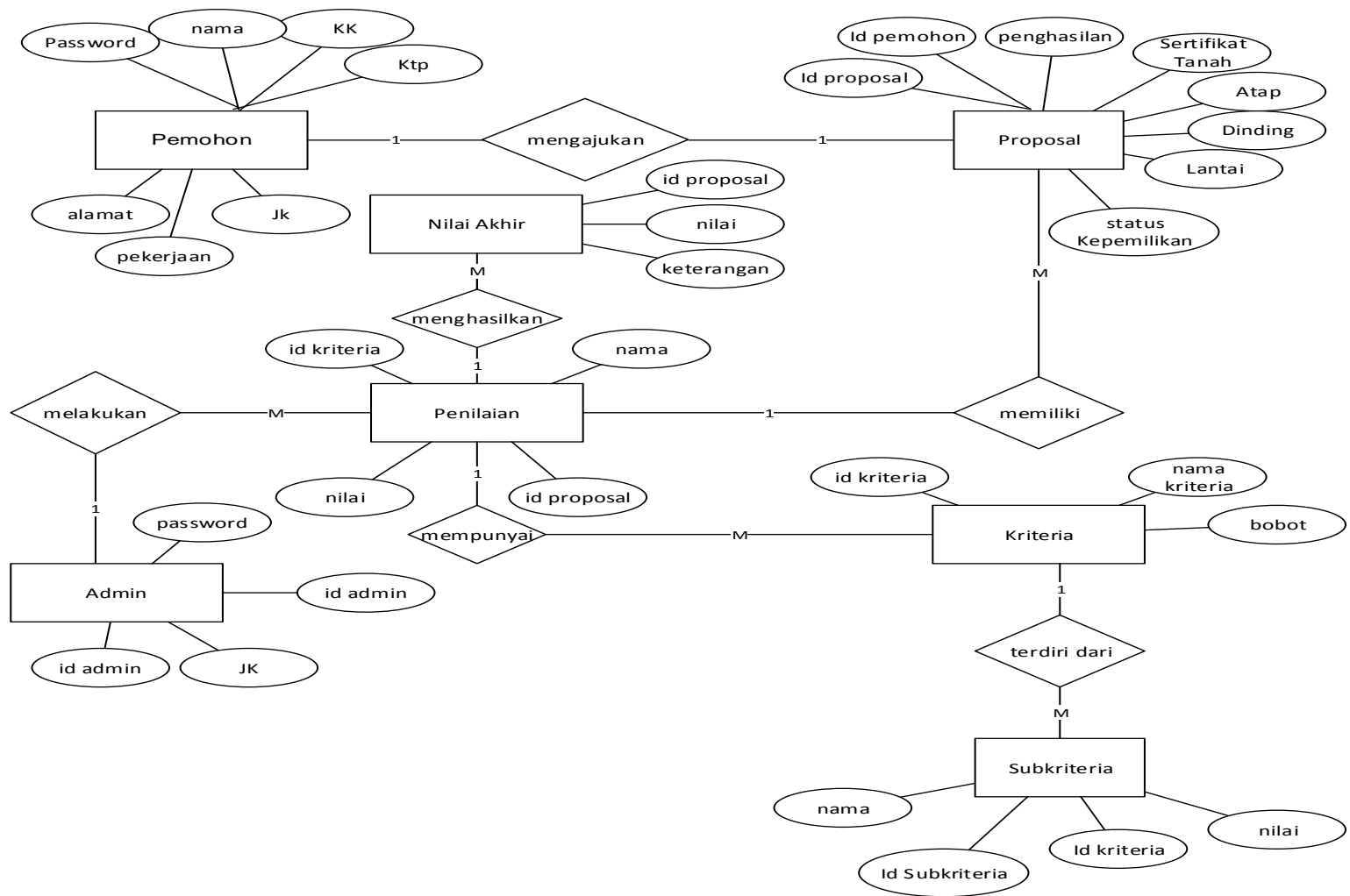

Sumber: (Penelitian, 2019)

Gambar 2. Entity Relationship Diagram 
3. Perhitungan Manual Metode Smart (Simple Multy Rating Technique)

1) Analisis proses penyeleksian penerima BSPS dengan Metode SMART, diperlukan kriteria-kriteria dan bobot untuk melakukan perhitunganya sehingga akan di dapat Penerima BSPS yang terbaik.

2) Data Kriteria

Tabel 1. Data Kriteria

\begin{tabular}{|l|l|l|c|}
\hline No & Variabel & \multicolumn{1}{|c|}{ Kriteria } & Nilai Bobot \\
\hline 1. & K1 & Penghasilan & $30 \%$ \\
\hline 2. & K2 & Atap & $20 \%$ \\
\hline 3. & K3 & Dinding & $20 \%$ \\
\hline 4. & K4 & Lantai & $20 \%$ \\
\hline 5. & K5 & Wc & $10 \%$ \\
\hline \multicolumn{2}{|l|}{ Jumlah } & $\mathbf{1 0 0} \%$ \\
\hline
\end{tabular}

A. Data Subkriteria

Tabel 2 Data Subkriteria

\begin{tabular}{|c|c|c|c|c|}
\hline No & Id & Kriteria & Sub Kriteria & Nilai \\
\hline \multirow[t]{3}{*}{1.} & \multirow[t]{3}{*}{ K1 } & \multirow[t]{3}{*}{ Penghasilan } & $<1000,000$ & 90 \\
\hline & & & $1.200,000-1.500,000$ & 80 \\
\hline & & & $>1.500,000$ & 70 \\
\hline \multirow[t]{3}{*}{2.} & \multirow[t]{3}{*}{$\mathrm{K} 2$} & \multirow[t]{3}{*}{ Atap } & Seng, injuk & 90 \\
\hline & & & Genteng, Asbes & 80 \\
\hline & & & Beton & 70 \\
\hline \multirow[t]{3}{*}{3.} & \multirow[t]{3}{*}{ K3 } & \multirow[t]{3}{*}{ Dinding } & Anyaman bambu, papan & 90 \\
\hline & & & Seng, triplek & 80 \\
\hline & & & Tembok,beton & 70 \\
\hline \multirow[t]{3}{*}{4.} & \multirow[t]{3}{*}{ K4 } & \multirow[t]{3}{*}{ Lantai } & Tanah, bambu,kayu & 90 \\
\hline & & & Semen & 80 \\
\hline & & & Keramik & 70 \\
\hline \multirow[t]{3}{*}{5.} & \multirow[t]{3}{*}{ K5 } & \multirow[t]{3}{*}{ Wc } & Tidak Punya & 90 \\
\hline & & & Bersama/Komunal & 80 \\
\hline & & & Sendiri & 70 \\
\hline
\end{tabular}

Tabel 3 Nilai Cout

\begin{tabular}{|c|c|c|c|c|c|c|}
\hline \multirow{2}{*}{ No } & \multirow{2}{*}{ Alternatif } & \multicolumn{5}{|c|}{ Kriteria } \\
\hline & & K1 & $\mathrm{K} 2$ & K3 & K4 & K5 \\
\hline 1. & Sarti & 90 & 90 & 80 & 80 & 80 \\
\hline 2. & Taryat & 80 & 90 & 90 & 90 & 90 \\
\hline 3. & Enih & 80 & 80 & 60 & 80 & 80 \\
\hline 4. & Maman & 80 & 80 & 90 & 90 & 60 \\
\hline 5. & Ayat & 80 & 80 & 80 & 60 & 80 \\
\hline 6. & Ikah & 90 & 90 & 80 & 90 & 60 \\
\hline 7. & Een & 80 & 90 & 60 & 80 & 80 \\
\hline 8. & Nunung & 90 & 90 & 80 & 80 & 60 \\
\hline 9. & Ade & 80 & 80 & 80 & 80 & 60 \\
\hline 10. & Iyus & 80 & 90 & 60 & 90 & 60 \\
\hline 11. & Endin & 60 & 80 & 80 & 80 & 90 \\
\hline 12. & Suherman & 90 & 80 & 80 & 60 & 60 \\
\hline 13. & Enoh & 80 & 80 & 90 & 80 & 60 \\
\hline 14. & Mia & 60 & 80 & 80 & 80 & 60 \\
\hline 15. & Sohibin & 90 & 80 & 80 & 80 & 60 \\
\hline 16. & Cicih & 80 & 80 & 90 & 90 & 80 \\
\hline 17. & Itang & 90 & 80 & 60 & 80 & 80 \\
\hline 18. & Emus & 90 & 80 & 80 & 90 & 90 \\
\hline 19. & Onih & 80 & 80 & 80 & 90 & 90 \\
\hline 20. & Edi & 90 & 90 & 80 & 90 & 60 \\
\hline
\end{tabular}


IJSE - Indonesian Journal on Software Engineering, Vol.5, No. 2, Desember 2019, 42-50 pISSN: 2461-0690 I elSSN: 2714-9935

\begin{tabular}{|l|l|l|l|l|l|l|}
\hline 21. & Uho & 80 & 80 & 80 & 60 & 60 \\
\hline 22. & Ading & 90 & 80 & 90 & 80 & 90 \\
\hline 23. & Uas & 80 & 90 & 80 & 60 & 80 \\
\hline 24. & Ade & 90 & 90 & 90 & 90 & 80 \\
\hline 25. & Amah & 80 & 80 & 80 & 80 & 80 \\
\hline 26. & Rahmat & 80 & 80 & 90 & 80 & 80 \\
\hline 27. & Jaja & 60 & 80 & 80 & 80 & 60 \\
\hline 28. & Miroh & 80 & 80 & 80 & 60 & 60 \\
\hline 29. & Oman & 80 & 80 & 90 & 80 & 80 \\
\hline 30. & Dodoh & 90 & 90 & 80 & 80 & 80 \\
\hline
\end{tabular}

Tabel 4 Nilai Utility

\begin{tabular}{|c|c|c|c|c|c|c|}
\hline \multirow[t]{2}{*}{ No } & \multirow[t]{2}{*}{ Alternatif } & \multicolumn{5}{|c|}{ Nilai Utility } \\
\hline & & K1 & K2 & $\mathrm{K} 3$ & K4 & K5 \\
\hline 1. & Sarti & 8,9 & 8,9 & 7,8 & 7,8 & 5,6 \\
\hline 2. & Taryat & 7,8 & 8,9 & 8,9 & 8,9 & 8,9 \\
\hline 3. & Enih & 7,8 & 7,8 & 5,6 & 7,8 & 7,8 \\
\hline 4. & Maman & 7,8 & 7,8 & 8,9 & 8,9 & 5,6 \\
\hline 5. & Ayat & 7,8 & 7,8 & 7,8 & 5,6 & 7,8 \\
\hline 6. & Ikah & 8,9 & 8,9 & 7,8 & 8,9 & 5,6 \\
\hline 7. & Een & 7,8 & 8,9 & 5,6 & 7,8 & 7,8 \\
\hline 8. & Nunung & 8,9 & 8,9 & 7,8 & 7,8 & 5,6 \\
\hline 9. & Ade & 7,8 & 7,8 & 7,8 & 7,8 & 5,6 \\
\hline 10. & lyus & 7,8 & 8,9 & 5,6 & 8,9 & 8,9 \\
\hline 11. & Endin & 5,6 & 7,8 & 7,8 & 7,8 & 8,9 \\
\hline 12. & Suherman & 8,9 & 7,8 & 7,8 & 5,6 & 5,6 \\
\hline 13. & Enoh & 7,8 & 7,8 & 8,9 & 7,8 & 8,9 \\
\hline 14. & Mia & 5,6 & 7,8 & 7,8 & 7,8 & 5,6 \\
\hline 15. & Sohibin & 8,9 & 7,8 & 7,8 & 7,8 & 5,6 \\
\hline 16. & Cicih & 7,8 & 7,8 & 8,9 & 8,9 & 7,8 \\
\hline 17. & Itang & 8,9 & 7,8 & 7,8 & 7,8 & 8,9 \\
\hline 18. & Emus & 8,9 & 7,8 & 7,8 & 8,9 & 8,9 \\
\hline 19. & Onih & 7,8 & 7,8 & 7,8 & 8,9 & 8,9 \\
\hline 20. & Edi & 8,9 & 8,9 & 7,8 & 8,9 & 5,6 \\
\hline 21. & Uho & 7,8 & 7,8 & 7,8 & 5,6 & 5,6 \\
\hline 22. & Ading & 8,9 & 7,8 & 8,9 & 7,8 & 8,9 \\
\hline 23. & Uas & 7,8 & 8,9 & 7,8 & 5,6 & 7,8 \\
\hline 24. & Ade & 8,9 & 8,9 & 8,9 & 8,9 & 7,8 \\
\hline 25. & Amah & 7,8 & 8,9 & 8,9 & 7,8 & 7,8 \\
\hline 26. & Rahmat & 7,8 & 7,8 & 8,9 & 7,8 & 7,8 \\
\hline 27. & Jaja & 5,6 & 7,8 & 7,8 & 7,8 & 5,6 \\
\hline 28. & Miroh & 7,8 & 7,8 & 7,8 & 5,6 & 5,6 \\
\hline 29. & Oman & 7,8 & 7,8 & 8,9 & 7,8 & 7,8 \\
\hline 30. & Dodoh & 8,9 & 8,9 & 7,8 & 7,8 & 7,8 \\
\hline
\end{tabular}

B. Menentukan Nilai Akhir

Rumus : $U(a i) \sum_{w j i=}^{m}$ wjui(ai)

1. Sarti

$$
\begin{gathered}
(8,9 \times 0,3)+(8,9 \times 0,2)+(7,8 \times 0,2)+(7,8 \times 0,2)+(5,6 \times 0,1) \\
=2,67+1,78+1,56+1,56+0,56=8,13
\end{gathered}
$$

\begin{tabular}{|c|c|c|c|c|c|c|c|}
\hline \multirow{2}{*}{ No } & \multirow{2}{*}{ Alternatif } & \multicolumn{5}{|c|}{ Nilai Akhir } & \multirow[b]{2}{*}{ Total nilai } \\
\hline & & K1 & K2 & K3 & K4 & K5 & \\
\hline 1. & Sarti & 2,67 & 1,78 & 1,56 & 1,56 & 0,56 & 8,13 \\
\hline
\end{tabular}

Tabel IV.14. Nilai Akhir 


\begin{tabular}{|l|l|l|l|l|l|l|l|}
\hline 2. & Taryat & 2,34 & 1,78 & 1,78 & 1,78 & 0,89 & 8,57 \\
\hline 3. & Enih & 2,34 & 1,56 & 1,12 & 1,56 & 0,78 & 7,36 \\
\hline 4. & Maman & 2,34 & 1,56 & 1,78 & 1,78 & 0,56 & 8,2 \\
\hline 5. & Ayat & 2,34 & 1,56 & 1,56 & 1,12 & 0,56 & 7,14 \\
\hline 6. & Ikah & 2,67 & 1,78 & 1,56 & 1,78 & 0,56 & 8,35 \\
\hline 7. & Een & 2,34 & 1,78 & 1,12 & 1,56 & 0,78 & 7,58 \\
\hline 8. & Nunung & 2,67 & 1,78 & 1,56 & 1,56 & 0,56 & 8,13 \\
\hline 9. & Ade & 2,34 & 1,56 & 1,56 & 1,56 & 0,56 & 7,58 \\
\hline 10. & lyus & 2,34 & 1,78 & 1,56 & 1,78 & 0,89 & 8,35 \\
\hline 11. & Endin & 1,68 & 1,56 & 1,56 & 1,56 & 0,89 & 7,25 \\
\hline 12. & Suherman & 2,67 & 1,56 & 1,56 & 1,12 & 0,56 & 7,47 \\
\hline 13. & Enoh & 2,34 & 1,56 & 1,78 & 1,56 & 0,89 & 8,13 \\
\hline 14. & Mia & 0,56 & 1,56 & 1,56 & 1,56 & 0,56 & 5,8 \\
\hline 15. & Sohibin & 2,67 & 1,56 & 1,56 & 1,56 & 0,56 & 7,91 \\
\hline 16. & Cicih & 2,34 & 1,56 & 1,56 & 1,78 & 0,78 & 8,2 \\
\hline 17. & Itang & 2,67 & 1,56 & 1,56 & 1,56 & 0,89 & 8,24 \\
\hline 18. & Emus & 2,67 & 1,56 & 1,56 & 1,78 & 0,89 & 8,46 \\
\hline 19. & Onih & 2,34 & 1,56 & 1,56 & 1,78 & 0,89 & 8,13 \\
\hline 20. & Edi & 2,67 & 1,78 & 1,56 & 1,78 & 0,56 & 8,35 \\
\hline 21. & Uho & 2,34 & 1,56 & 1,56 & 1,12 & 0,56 & 7,14 \\
\hline 22. & Ading & 2,67 & 1,56 & 1,56 & 1,56 & 0,89 & 8,24 \\
\hline 23. & Uas & 2,34 & 1,78 & 1,56 & 1,12 & 0,78 & 7,58 \\
\hline 24. & Ade & 2,67 & 1,78 & 1,78 & 1,78 & 0,78 & 8,79 \\
\hline 25. & Amah & 2,34 & 1,78 & 1,78 & 1,56 & 0,56 & 7,58 \\
\hline 26. & Rahmat & 2,34 & 1,56 & 1,56 & 1,56 & 0,78 & 7,8 \\
\hline 27. & Jaja & 1,68 & 1,56 & 1,56 & 1,56 & 0,56 & 6,92 \\
\hline 28. & Miroh & 2,34 & 1,56 & 1,56 & 1,12 & 0,56 & 7,14 \\
\hline 29. & Oman & 2,34 & 1,56 & 1,78 & 1,56 & 0,78 & 8,2 \\
\hline 30. & Dodoh & 2,67 & 1,78 & 1,56 & 1,56 & 0,78 & 8,35 \\
\hline & & & & & & & \\
\hline
\end{tabular}

Tabel IV.15. Hasil Seleksi Penerima BSPS

\begin{tabular}{|l|l|c|c|l|l|c|c|}
\hline No & Pemohon & Nilai & Keterangan & No & Pemohon & Nilai & Keterangan \\
\hline 1. & Sarti & 8,13 & Layak & 16. & Cicih & 8,2 & Layak \\
\hline 2. & Taryat & 8,57 & Layak & 17. & Itang & 8,24 & Layak \\
\hline 3. & Enih & 7,36 & Tidak layak & 18. & Emus & 8,46 & Layak \\
\hline 4. & Maman & 8,2 & Layak & 19. & Onih & 8,13 & Layak \\
\hline 5. & Ayat & 7,14 & Tidak layak & 20. & Edi & 8,35 & Layak \\
\hline 6. & lkah & 8,35 & Layak & 21. & Uho & 7,14 & Tidak layak \\
\hline 7. & Een & 7,58 & Tidak layak & 22. & Ading & 8,24 & Layak \\
\hline 8. & Nunung & 8,13 & Layak & 23. & Uas & 7,58 & Tidak layak \\
\hline 9. & Ade & 7,56 & Tidak layak & 24. & Ade & 8,79 & Layak \\
\hline 10. & lyus & 8,35 & Layak & 25. & Amah & 7,58 & Tidak layak \\
\hline 11. & Endin & 7,25 & $\begin{array}{c}\text { Tidak } \\
\text { Layak }\end{array}$ & 26. & Rahmat & 7,8 & Tidak layak \\
\hline 12. & Suherman & 7,47 & Tidak & 27. & Jaja & 6,92 & Tidak layak \\
\hline Layak & & & & & \\
\hline 13. & Enoh & 8,13 & Layak & 28. & Miroh & 7,14 & Tidak layak \\
\hline 14. & Mia & 5,8 & Tidak layak & 29. & Oman & 8,2 & Layak \\
\hline 15. & Sohibin & 7,91 & Tidak layak & 30. & Dodoh & 8,35 & Layak \\
\hline
\end{tabular}

Jadi dari hasil analisis sistem pendukung keputusan penerima BSPS Menggunakan Metode Smart dari sample 30 Pemohon yang diseleksi terdapat 16 orang yang layak menerima Bantuan Stimulan Perumahan Swadaya, dan 14 orang yang tidak layak menerima Bantuan Stimulan Perumahan Swadaya. 
IJSE - Indonesian Journal on Software Engineering, Vol.5, No. 2, Desember 2019, 42-50 pISSN: 2461-0690 I elSSN: 2714-9935

\section{Implementasi}

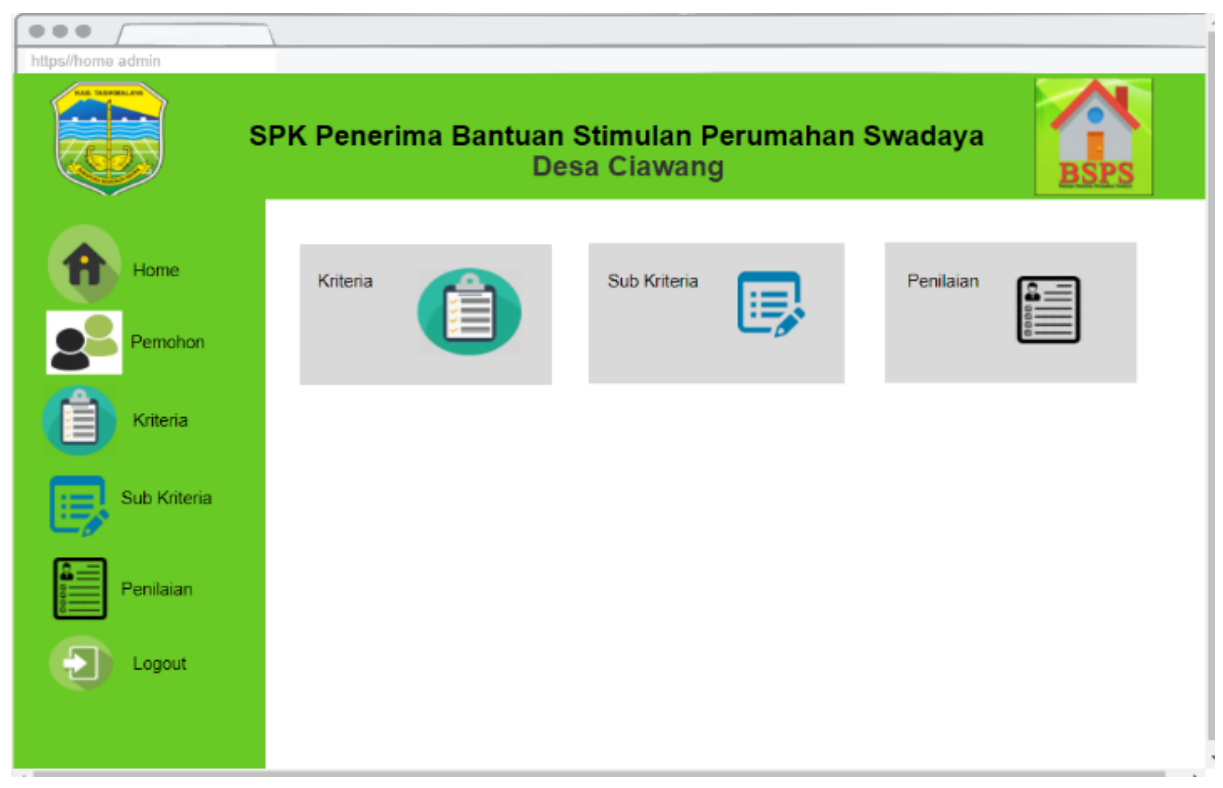

Gambar 3. Halaman Utama Admin

\begin{tabular}{|l|c|c|c|}
\hline & SPK Penerima Bantuan Stimulan Perumahan Swadaya \\
Desa Clawang
\end{tabular}

Gambar 4. Halaman Kriteria

\section{E. KESIMPULAN}

Dengan adanya sistem pendukung keputusan penerima BSPS berbasis website, dapat mempermudah dalam pendataan pemohon yang mengajukan BSPS. Metode Smart di implementasikan pada pemilihan calon penerima BSPS dan menghasilkan perhitungan yang lebih objektif dalam mengambil keputusan penerima BSPS. sistem pendukung keputusan ini bisa dijadikan sebagai alternatif dalam mendukung Keputusan Penerima BSPS. 


\section{REFERENSI}

Informatika, M., \& Terapan, F. I. (2015). Aplikasi Data Kemiskinan Kabupaten Indramayu Berbasis Web Dan Android Mellyantika. 1(1), 482-486.

Khouf, R. H., Informatika, P. S., Komunikasi, F., Informatika, D. A. N., \& Surakarta, U. M. (2017). Kecamatan Sambirejo Dengan Menggunakan Metode Simple Additive.

Qomaria, A. (2015). Dampak Sosial Ekonomi dan Lingkungan Program Bantuan Stimulan Perumahan Swadaya di Kelurahan Meri Kota Mojokerto. Kebijakan Dan Manajemen Publik, 3(1), 1-7.

Sanjaya, A., Khairina, D. M., \& Maharani, S. (2015). Rekomendasi Pembelian Grosir Pada Toko Mainan Menggunakan Metode Simple Multi Attribute Rating Technique (SMART) dengan Google Maps. Prosiding Seminar Sains Dan Teknologi FMIPA Unmul, 1(1).

Syahputra, H., Syahrizal, M., Nasution, S. D., \& Purba, B. (2019). SPK Pemilihan Konten Youtube Layak Tonton Untuk Anak-Anak Menerapkan Metode Additive Ratio Assessment ( ARAS ). 678-685. 